\title{
Effect of an LHRH agonist on pituitary and testicular function in rhesus monkeys
}

\author{
K. Sundaram, R. B. Thau, M. Goldstein, D. M. Phillips, J. Rivier*, \\ W. Vale* and C. W. Bardin \\ The Population Council, 1230 York Avenue, New York, New York 10021, and \\ *The Peptide Biology Laboratory, Salk Institute, La Jolla, California 92138, U.S.A.
}

\begin{abstract}
Summary. Male rhesus monkeys were given $100 \mu \mathrm{g}$ [(imBzl)-D-His ${ }^{6}$, Pro $\left.^{9}-\mathrm{NEt}\right]-\mathrm{LHRH}$ (LHRH-A), a potent LHRH agonist, s.c. daily for 40 weeks. The first dose of LHRHA caused acute increases ( $2-4 \mathrm{~h}$ after injection) in serum LH (50-fold), FSH (2-5-fold) and testosterone (15-fold) concentrations. Chronic treatment led to a $95 \%$ decrease in LH and FSH responses. In spite of a marked decrease in LH response the effect on testosterone response was less evident. Administration of 50 i.u. hCG to control and LHRH-A-treated animals showed that the testicular steroidogenic response was unimpaired by the chronic treatment. Evaluation of the electroejaculated semen at regular intervals showed that there was no consistent reduction in the sperm count of LHRH-A-treated monkeys. Testicular biopsies showed that normal spermatogenesis was occurring in all treated animals, but testicular volume was significantly decreased. These results suggest that, in rhesus monkeys, the pituitary is more susceptible to desensitization by chronic LHRH agonist treatment than are the testes, and that LHRH agonists do not have direct antitesticular effect in rhesus monkeys.
\end{abstract}

\section{Introduction}

It is well established that chronic administration of LHRH agonists to male rats leads to a reduction in testicular androgen production and a disruption of spermatogenesis (Labrie et al., 1978; Corbin, Beattie, Jones \& Bex, 1979; Rivier, Rivier \& Vale, 1979). This led to the hope that these peptides may provide a new approach to regulating fertility in men. Attempts to explore the mechanism of action of these peptides showed that there are wide differences in the susceptibility of animals of different species to the anti-testicular effects of LHRH agonists. For example, dogs were much more sensitive to the anti-testicular effects of LHRH agonist than rats (Sandow, Rechenberg, Baeder \& Engebart, 1980; Vickery, 1981). Furthermore, in contrast to rats, mice were quite insensitive to the pituitary-mediated as well as the direct antitesticular effects of LHRH agonists (Bex, Corbin \& France, 1982; Wang et al., 1983). Studies of rhesus monkeys suggest that they are comparatively resistant to the anti-testicular effects of LHRH agonists (Akhtar, Wickings, Zaidi \& Nieschlag, 1982; Resko, Belanger \& Labrie, 1982; Sundaram, Connell, Bardin, Samojlik \& Schally, 1982). The present study was designed to examine whether (1) chronic treatment of male rhesus monkeys with a potent LHRH agonist will inhibit testicular function, and (2) the LHRH agonist has extrapituitary effects on the testes.

\section{Materials and Methods}

Hormone preparations. The LHRH agonist, [(imBzl)-D-His ${ }^{6}$, Pro $\left.^{9}-\mathrm{NEt}\right]-\mathrm{LHRH}$ (LHRH-A) was synthesized as previously described and its in-vitro LH-releasing activity was shown to be 210 times 
greater than that of LHRH (Rivier \& Vale, 1978; Vale, Rivier, Perrin \& Rivier, 1979). Its in-vivo LH-releasing activity in the rat has also been reported (Cao, Sundaram, Bardin, Rivier \& Vale, 1982). HCG was purchased from Sigma Chemical Co. (St Louis, MO).

Animals and treatment. Twelve adult male rhesus monkeys (Macaca mulatta) housed in individual cages in air-conditioned quarters with an artificial photoperiod of $12 \mathrm{~h} /$ day were used. Animals were provided with water ad libitum and fed a commercial diet supplemented with fresh fruit. All blood samples were withdrawn from the femoral veins of unsedated animals, and the serum samples were stored at $-20^{\circ} \mathrm{C}$. Six animals received $100 \mu \mathrm{g}$ LHRH-A daily for 40 weeks. LHRH-A was dissolved in $0.5 \mathrm{ml}$ sterile saline $(0.15 \mathrm{M}-\mathrm{NaCl})$ and administered s.c. between $09: 00$ and 10:00 $\mathrm{h}$ after collecting basal blood samples. To evaluate the acute hormonal response of the pituitary and testes to chronic LHRH-A treatment, blood samples were collected $0,2,4,8$ and $24 \mathrm{~h}$ after LHRH-A injection at the beginning and at selected times during the treatment period. Finally, $24 \mathrm{~h}$ after the last dose of LHRH-A, 50 i.u. hCG were given s.c. to treated and control animals and the serum testosterone levels were measured at frequent intervals.

Throughout the experiment, the monkeys were electroejaculated at regular intervals and the semen evaluated by previously described procedures (Sundaram et al., 1982). The length and width of the testes were measured with calipers and the testicular volume estimated (Wickings \& Nieschlag, 1980). At the end of the study, testicular biopsy was performed on all animals; the tissues were fixed in $2.5 \%$ glutaraldehyde buffered with $0.2 \mathrm{M}$-collidine, embedded in epon and 1.0 $\mu \mathrm{m}$ sections were stained with Toluidine blue for microscopic examination.

Hormone assays. Serum LH levels were determined by an in-vitro bioassay method based on the production of testosterone by dispersed mouse Leydig cells (Sundaram et al., 1982). A monkey pituitary gonadotrophin preparation (LER-1909-2) was used as standard and the serum LH levels are expressed as $\mu$ g LER-1909-2/ml. The limit of detection was $80 \mathrm{ng} / \mathrm{ml}$ serum. The intra- and inter-assay coefficients of variation were $12.4 \%$ and $18.6 \%$, respectively. Serum FSH was determined using the reagents provided by NIAMDD. The limit of sensitivity was $2.5 \mu \mathrm{g}$ LER1909-2. Intra- and inter-assay coefficients of variation were $6.5 \%$ and $9.6 \%$, respectively (Thau, Yamamoto, Sundaram \& Spinola, 1983). RIA of serum testosterone was performed using an antiserum raised against testosterone-3-oxime-bovine serum albumin according to the procedure of Collins, Mansfield, Alladina \& Sommerville (1972). The limit of sensitivity was $35 \mathrm{pg} / \mathrm{ml}$ serum. The cross-reaction of the antiserum utilized was $60 \%$ with dihydrotestosterone. The dihydrotestosterone concentration in monkeys is 10 times less than that of testosterone and therefore does not add significantly to estimations of testosterone (Sundaram et al., 1982). Intra- and inter-assay coefficients of variation were $8.5 \%$ and $13.1 \%$, respectively. Statistical comparisons of results were made using a computer programme for analysis of variance (Nie, Hull, Jenkins, Steinbrenner \& Bent, 1982).

\section{Results}

\section{Effect of LHRH-A on pituitary function}

The effect of chronic treatment with LHRH-A (100 $\mu \mathrm{g}$ daily) on serum gonadotrophin responses is shown in Text-fig. 1. In response to the first injection there was a rapid increase in $\mathrm{LH}$ (50-fold) and FSH (2.5-fold) levels. The peak gonadotrophin concentrations were attained by $4 \mathrm{~h}$, and by $24 \mathrm{~h}$ they had returned to baseline values. After repeated daily administration of LHRH-A there was a significant reduction $(P<0.01)$ in acute LH and FSH responses. However, the basal LH and FSH levels, observed just before each injection of LHRH-A, were not significantly different from those before treatment. 

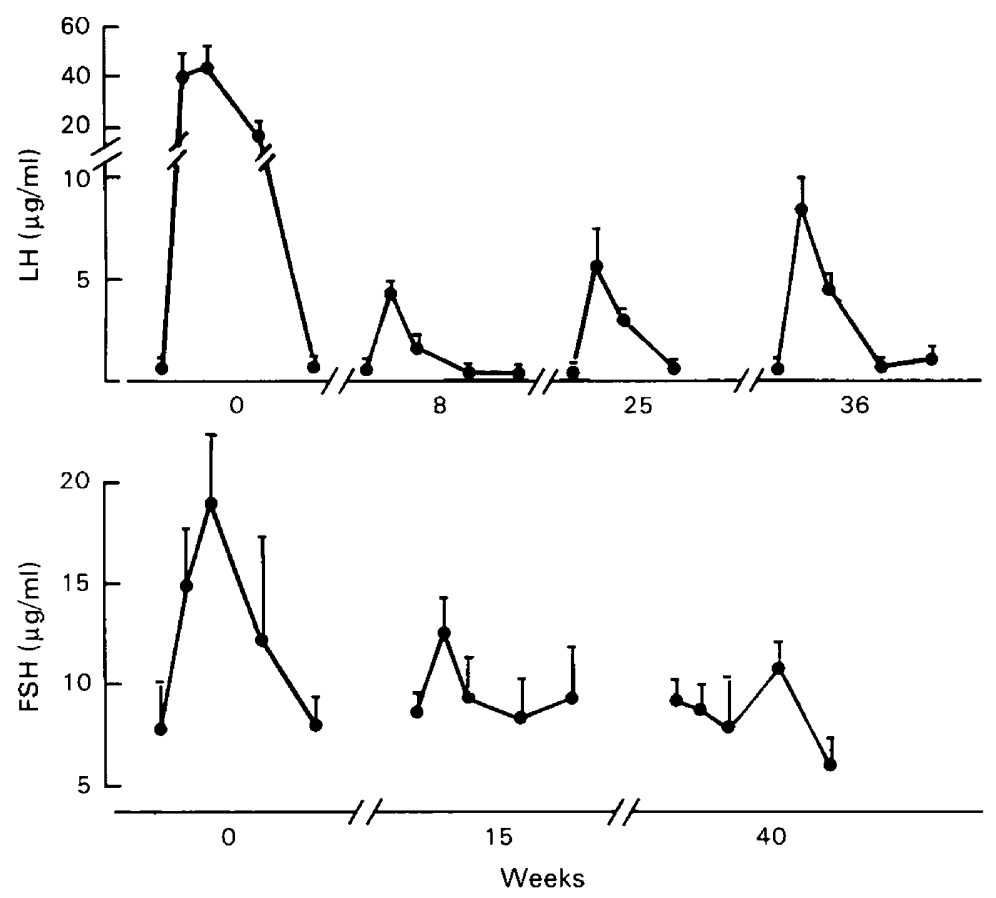

Text-fig. 1. Acute changes in mean serum LH and FSH concentrations after the administration of $100 \mu \mathrm{g}$ LHRH-A at the beginning and at selected times during chronic treatment. The points in each curve represent hormone levels at $0,2,4,8$ and $24 \mathrm{~h}$ after treatment, sequentially. Values are mean and s.e.m. for 6 animals.

\section{Effect of LHRH-A on Leydig cell function}

The first injection of LHRH-A caused a 15 -fold increase in serum testosterone levels (Text-fig. 2). The peak levels were maintained for up to $8 \mathrm{~h}$ and had not returned to preinjection levels by $24 \mathrm{~h}$ when the next dose of LHRH-A was given. In contrast to gonadotrophins, the testosterone response was much less affected by the chronic LHRH-A treatment. Large increases in serum testosterone were noted after each dose of LHRH-A. However, the testosterone concentrations remained elevated for a shorter period and returned to baseline by $8 \mathrm{~h}$. The basal values after chronic LHRH-A treatment were slightly but not significantly lower than the pretreatment levels. The average testosterone values in control animals ranged from $3.2 \pm 0.7$ to $7.2 \pm 1.6 \mathrm{ng} / \mathrm{ml}$ over a period of several months.

To investigate the effect of chronic LHRH-A treatment on the testicular steroidogenic potential, control and treated animals were given hCG (50 i.u.) and the serum testosterone levels measured. The hCG induced a rapid increase in serum testosterone concentrations in both groups of animals (Text-fig. 3). The values remained elevated for 2 days before declining. The response of the LHRH-A-treated animals was significantly greater $(P<0.01$, ANOVA) than that of the controls.

\section{Effect of $L H R H-A$ on seminiferous epithelium}

As shown in Table 1, chronic treatment with LHRH-A led to a gradual reduction in testicular volume that was significant $(P<0.01)$ by 24 weeks of treatment. At 20 weeks after cessation of treatment the testicular volume was restored to pretreatment values. The sperm output per ejaculate fluctuated widely in both groups of animals. There was no consistent decrease in the 


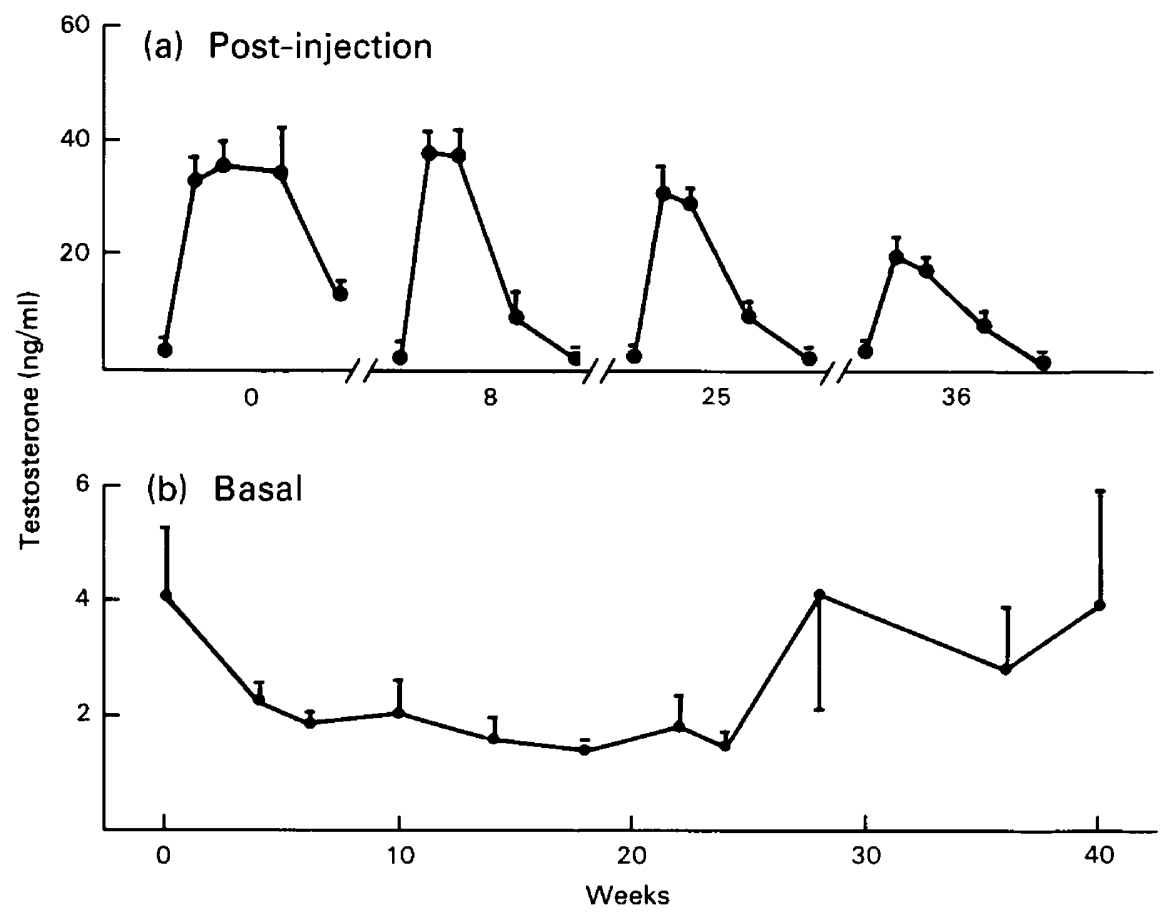

Text-fig. 2. Serum testosterone concentrations after the administration of $100 \mu \mathrm{g}$ LHRH-A at the beginning and at different intervals during the chronic treatment; in (a) the points in each curve represent concentrations at $0,2,4,8$ and $24 \mathrm{~h}$ after treatment, sequentially, and in (b) basal testosterone concentration in blood samples collected immediately before administration of LHRH-A at different times during treatment. Values are mean and s.e.m. for 6 animals.

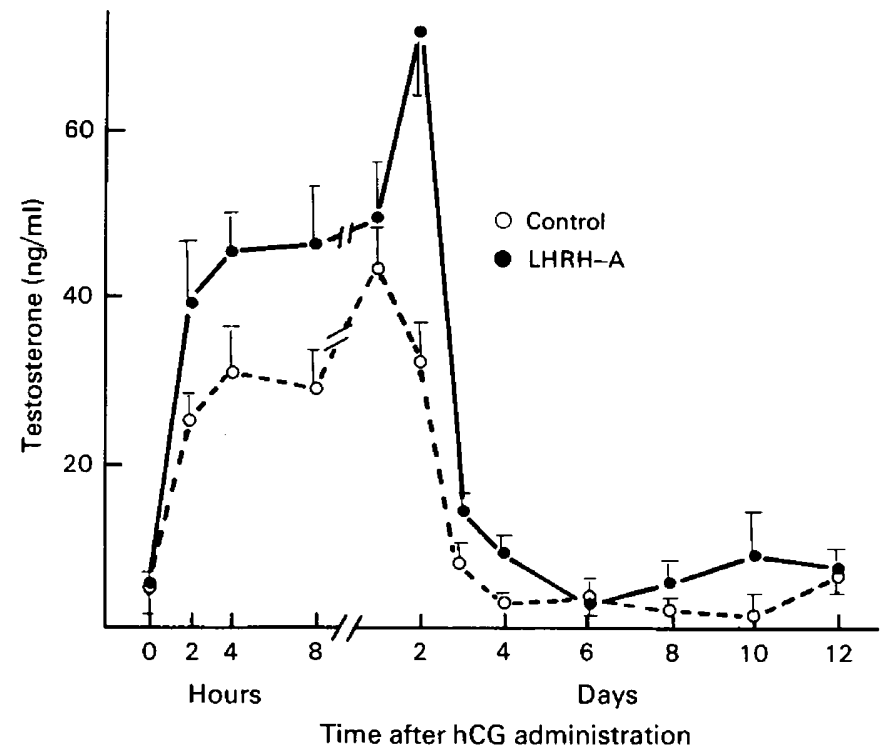

Text-fig. 3. Changes in serum testosterone concentrations after the administration of hCG (50 i.u., s.c.) to control and LHRH-A treated animals; hCG was given $24 \mathrm{~h}$ after the last LHRH-A injection. Values are mean and s.e.m. for 6 animals. 
Table 1. Testicular volume and sperm count (mean \pm s.e.m.) of monkeys treated for 40 weeks with LHRH-A ( $100 \mu \mathrm{g}$ daily)

\begin{tabular}{|c|c|c|c|c|c|c|c|c|}
\hline & \multicolumn{8}{|c|}{ Week } \\
\hline & 0 & 8 & 16 & 20 & 24 & 30 & 37 & Recovery \\
\hline \multicolumn{9}{|c|}{ Testicular volume $(\mathrm{ml}) \dagger$} \\
\hline $\begin{array}{l}\text { Control } \\
\text { LHRH- }\end{array}$ & $30 \cdot 6 \pm 5 \cdot 3$ & $34 \cdot 4 \pm 5 \cdot 1$ & $31 \cdot 1 \pm 5 \cdot 6$ & $33 \cdot 2 \pm 6 \cdot 6$ & $32 \cdot 7 \pm 6 \cdot 6$ & $31 \cdot 1 \pm 5 \cdot 5$ & $36 \cdot 2 \pm 5 \cdot 8$ & $36 \cdot 2 \pm 4 \cdot 4$ \\
\hline $\mathbf{A}^{*}$ & $29 \cdot 3 \pm 5 \cdot 9$ & $27 \cdot 4 \pm 5 \cdot 0$ & $26 \cdot 8 \pm 5 \cdot 3$ & $26 \cdot 8 \pm 5 \cdot 3$ & $22 \cdot 1 \pm 3 \cdot 9$ & $20 \cdot 8 \pm 3 \cdot 7$ & $22 \cdot 5 \pm 5 \cdot 0$ & $33 \cdot 4 \pm 6 \cdot 4$ \\
\hline \multicolumn{9}{|c|}{ Sperm count/ejaculate $\left(\times 10^{-5}\right)$} \\
\hline Control & $590 \underset{(6)}{ \pm} 160$ & $417 \underset{(6)}{ \pm} 70$ & $487 \underset{(6)}{ \pm} 181$ & $404 \underset{(6)}{ \pm} 135$ & $378 \underset{(6)}{ \pm} 101$ & $468 \pm \frac{ \pm}{(5)} 104$ & $385 \pm 98$ & $303 \underset{(6)}{ \pm} 68$ \\
\hline LHRH-A & $403 \pm \frac{165}{(6)}$ & $567 \underset{(6)}{296}$ & $473 \pm \frac{ \pm}{(6)} 119$ & $314 \pm \frac{ \pm}{(3)} 198$ & $703 \pm \frac{ \pm}{(4)} 114$ & $149 \underset{(4)}{ \pm} 65$ & $421 \pm \underset{(4)}{ \pm} 103$ & $146 \pm \frac{88}{(4)}$ \\
\hline
\end{tabular}

Values are mean \pm s.e.m. for 6 animals/group or for those that ejaculated (no. in parentheses).

$\dagger$ Total volume of both testes.

$\$ 20$ weeks after cessation of treatment.

* Significantly different from control $(P<0.05)$ (ANOVA).

sperm count. After 18 weeks of LHRH-A treatment, 2 of the 6 animals lost their ejaculatory response and this was not restored up to 6 months after cessation of treatment. A loss of ejaculatory response occasionally occurred in untreated animals. Histological examination of testicular biopsies taken at the end of treatment showed that normal spermatogenesis was occurring in all animals including the 2 that had lost their ejaculatory response. Although the seminiferous tubular diameter of the LHRH-A-treated animals was smaller $(161 \pm 6 \mu \mathrm{m})$, it was not significantly different from that of the control animals $(178 \pm 11 \mu \mathrm{m})$.

\section{Discussion}

In the present study, chronic treatment of male rhesus monkeys with LHRH-A led to a desensitization of the pituitary characterized by an impairment of LH and FSH responses. However, even prolonged treatment failed to abolish the gonadotrophin response. After each injection serum LH rose several fold above control values and produced a strong testicular steroidogenic response. In spite of a clear desensitization of the pituitary, there was no evidence for reduced responsiveness of the testes. The small decrease in the duration of testosterone response and an earlier return of testosterone to baseline values reflect the changes in the pattern of LH response rather than an impairment of testicular steroidogenesis. Similar findings have been described in male monkeys chronically treated with $25 \mu \mathrm{g}$ [D-Ser-(TBU) ${ }^{6}$,Pro ${ }^{9}-\mathrm{NEt}$ ]-LHRH, an agonist 40 times more potent than LHRH (Resko et al., 1982). When monkeys were treated with relatively large doses $\left(500 \mu \mathrm{g}\right.$ daily) of [D-Trp $\left.{ }^{6}\right]$-LHRH (biopotency, $60 \times \mathrm{LHRH}$ ), a complete loss of testicular steroidogenic response and very low basal testosterone concentrations were seen only in animals in which LH levels failed to rise above basal values after agonist administration (Sundaram et al., 1982). Similarly, when monkeys were chronically treated with [D-Ser(TBU) ${ }^{6}$, Pro $^{9}-\mathrm{NEt}$-LHRH $(2 \mu \mathrm{g} / \mathrm{h}$, s.c.) by means of osmotic minipumps, very low serum LH and testosterone levels and a complete loss of pituitary response to LHRH stimulation were obtained (Akhtar, Marshall, Wickings \& Nieschlag, 1983). Very low testosterone levels have been recorded in male baboons implanted s.c. with LHRH agonist pellets (Vickery \& McRae, 1980). In the above studies it was not ascertained whether the loss of testicular steroidogenic response was consequent to a loss of gonadotrophin response or whether there was a desensitization of the testes. In the present study, the testicular steroidogenic response to hCG was unimpaired or even superior in the LHRH-A-treated monkeys. Taken together these observations suggest that a decline in testicular function in monkeys during chronic LHRH agonist treatment is closely linked to a decline in gonadotrophin secretion. 
In contrast to dogs and rats, rhesus monkeys and mice seem to be relatively resistant to the antitesticular effects of LHRH agonists (Vickery, 1981; Bex et al., 1982). On the other hand, men seem to be quite sensitive to LHRH agonist effects (Bergquist, Nillius, Bergh, Skarin \& Wide, 1979; Linde et al., 1981; Faure et al., 1982). A marked decrease in gonadotrophin and testosterone concentrations followed by a loss of libido occurred in men treated daily with $50 \mu \mathrm{g}$ [D-Trp ${ }^{6}$, Pro ${ }^{9}$ NEt]-LHRH (Linde et al., 1981). There are also species differences in the susceptibility to the direct, non-pituitary-mediated antigonadal effects of LHRH agonists (Asch, Eddy \& Schally, 1981; Wang et al., 1983). A direct effect of LHRH-A on monkey testes is unlikely because testicular receptors for LHRH could not be detected (Clayton \& Huhtaniemi, 1982). Furthermore, the testicular steroidogenic response of monkeys to exogenous gonadotrophin stimulation was unimpaired after chronic LHRH-A treatment (this study).

It is generally believed that the decrease in testicular LH receptors and androgen secretion induced by chronic treatment with LHRH agonist is mediated via their action on the pituitary. The mechanism by which disruption of spermatogenesis occurs is not clear. Chronic treatment of rats with LHRH agonists increases serum gonadotrophin levels, decreases testicular LH and FSH receptor concentration and disrupts spermatogenesis (Labrie et al., 1978); the increased gonadotrophin levels were suggested as being due to degeneration of Leydig and Sertoli cell function leading to an escape of the pituitary from gonadal feedback inhibition. In other studies, high LH and FSH concentrations were attributed to a transient pituitary stimulatory effect of LHRH agonist since baseline gonadotrophin levels were normal or lower (Rivier et al., 1979; Bergquist et al., 1979). In the present study prolonged treatment of rhesus monkeys with LHRH-A caused a dramatic reduction in the magnitude of acute FSH responses but the basal levels were in the normal range. In spite of this, there was significant decrease in testicular volume in the present as in earlier studies (Akhtar et al., 1982). A decrease in testicular volume in rhesus monkeys immunized selectively against FSH has been reported (Wickings, Usadel, Dathe \& Nieschlag, 1980). The reason for the decrease in testicular volume in the LHRH-A-treated monkeys in the present study is not clear. LHRH-agonist treatment of rats leads to a decrease in testicular FSH receptors which may lead to a decrease in the testicular response to the biological effects of FSH. Whether such mechanisms are operating in the monkey testis is not known.

In conclusion, this study shows that the rhesus monkey is highly resistant to the anti-testicular effects of intermittent treatment with LHRH agonists. In addition; the results of this study coupled with those of other investigators suggest that any inhibition of spermatogenesis in the rhesus monkey would require a sustained inhibition of pituitary gonadotrophin secretion and would be accompanied by a marked deficiency in androgen production. Finally, it is concluded that LHRH agonists do not exert direct inhibitory effects on the testes in rhesus monkeys.

We thank the NIAMDD for the gift of hormones and reagents and Ms Kathryn G. Connell for technical assistance. This work was funded in part by NIH Grant HD 13541 and was undertaken as part of the contraceptive development programme sponsored and co-ordinated by the International Committee for Contraception Research of The Population Council Inc., New York. The financial support provided by the International Development Research Centre of Canada, the U.S. Agency for International Development (Grant AID/pha 1116), the Ford Foundation, the Rockefeller Foundation and the George J. Hecht Fund is gratefully acknowledged. The content of this report does not necessarily reflect the policy of any of the funding sources.

\section{References}

Ahktar, F.B., Wickings, E.J., Zaidi, P. \& Nieschlag, E. (1982) Pituitary and testicular function in sexually mature rhesus monkeys under high-dose LRHagonist treatment. Acta endocr., Copenh. 101, 113118.
Akhtar, F.B., Marshall, G.R., Wickings, E.J. \& Nieschlag, E. (1983) Reversible induction of azoospermia in rhesus monkeys by constant infusion of a gonadotropin-releasing hormone agonist using osmotic minipumps. J. clin. Endocr. Metab. 56, 534-540. 
Asch, R.H., Eddy, C.A. \& Schally, A.V. (1981) Lack of luteolytic effect of D-Trp ${ }^{6}$-LHRH in hypophysectomized rhesus monkeys (Macaca mulatta). Biol. Reprod. 25, 963-968.

Bergquist, C., Nillius, S.J., Bergh, T., Skarin, B. \& Wide, L. (1979) Inhibitory effects on gonadotrophin secretion and gonadal function in men during chronic treatment with a potent stimulatory luteinizing hormone-releasing hormone analogue. Acta endocr., Copenh. 91, 601-608.

Bex, F.J., Corbin, A. \& France, E. (1982) Resistance of the mouse to the antifertility effects of LHRH agonists. Life Sci. 30, 1263-1269.

Cao, Y.-Q., Sundaram, K., Bardin, C.W., Rivier, J. \& Vale, W. (1982) Direct inhibition of testicular steroidogenesis and gonadotrophin receptor levels by [(imBzl)-D-His ${ }^{6}$, Pro $\left.^{9}-\mathrm{NEt}\right] \mathrm{GnRH}$ and [D-Trp ${ }^{6}$, Pro $^{9}-$ NEt]GnRH, potent agonists of GnRH. Int. J. Androl. 5, 158-170.

Clayton, R.N. \& Huhtaniemi, I.T. (1982) Absence of gonadotropin-releasing hormone receptors in human gonadal tissue. Nature, Lond. 299, 56-59.

Collins, W.P., Mansfield, M.D., Alladina, N.S. \& Sommerville, I.F. (1972) Radioimmunoassay of plasma testosterone. J. Steroid Biochem. 3, 333-348.

Corbin, A., Beattie, C.W., Jones, R. \& Bex, F. (1979) Peptide contraception: antifertility properties of LHRH analogues. Int. J. Gynaec. Obstet. 16, 359-372.

Faure, N., Labrie, F., Lemay, A., Belanger, A., Gourdeau, Y., Laroche, B. \& Robert, G. (1982) Inhibition of serum androgen levels by chronic intranasal and subcutaneous administration of a potent luteinizing hormone-releasing hormone ( $\mathrm{LH}-\mathrm{RH}$ ) agonist in adult men. Fert. Steril. 37, 416-424.

Labrie, F., Auclair, C., Cusan, L., Kelly, P.A., Pelletier, G. \& Ferland, L. (1978) Inhibitory effect of LHRH and its agonists on testicular gonadotrophin receptors and spermatogenesis in the rat. Int. J. Androl., Suppl. 2, 303-318.

Linde, R., Doelle, G.C., Alexander, N., Kirchner, F., Vale, W., Rivier, J. \& Rabin, D. (1981) Reversible inhibition of testicular steroidogenesis and spermatogenesis by a potent gonadotropin-releasing hormone agonist in normal men. N. Engl. J. Med. 305, 663667.

Nie, N.H., Hull, C.H., Jenkins, J.G., Steinbrenner, K. \& Bent, D.H. (1982) In Statistical Package for the Social Sciences, pp. 398-433. McGraw-Hill, New York.

Resko, J.A., Belanger, A. \& Labrie, F. (1982) Effects of chronic treatment with a potent luteinizing hormone releasing hormone agonist on serum luteinizing hormone and steroid levels in the male rhesus monkey. Biol. Reprod. 26, 378-384.

Rivier, C., Rivier, J. \& Vale, W. (1979) Chronic effects of (D-Trp ${ }^{6}, \mathrm{Pro}^{9}-\mathrm{NEt}$ ) luteinizing hormone-releasing factor on reproductive processes in the male rat. Endocrinology 105, 1191-1201.

Rivier, J.E. \& Vale, W.W. (1978) [D-pGlu'D-Phe ${ }^{2}$,D$\operatorname{Trp}^{3,6}$ ]-LRF. A potent luteinizing hormone releasing factor antagonist in vitro and inhibitor of ovulation in the rat. Life Sci. 23, 869-876.

Sandow, J., Rechenberg, W., Baeder, C. \& Engebart, K. (1980) Antifertility effects of an LHRH analogue in male rats and dogs. Int. J. Fertil. 25, 213-221.

Sundaram, K., Connell, K.G., Bardin, C.W., Samojlik, E. \& Schally, A.V. (1982) Inhibition of pituitarytesticular functions with [D-Trp $\left.{ }^{6}\right]$ luteinizing hormone-releasing hormone in rhesus monkeys. Endocrinology 110, 1308-1314.

Thau, R.B., Yamamoto, Y., Sundaram, K. \& Spinola, P.G. (1983) Human chorionic gonadotropin stimulates luteal function in rhesus monkeys immunized against the $\beta$-subunit of ovine luteinizing hormone. Endocrinology 112, 277-283.

Vale, W., Rivier, C., Perrin, M. \& Rivier, J. (1979) LRF agonists and fertility regulation in the male. In Peptides: Structure and Biological Function, pp. 781793. Eds E. Gross \& J. Meienhoff. Pierce Chemical Co., Rockford.

Vickery, B.H. (1981) Physiology and antifertility effects of LHRH and agonistic analogs in male animals. In LHRH Peptides as Female and Male Contraceptives, pp. 275-290. Eds G. I. Zatuchni, J. D. Shelton \& J. J. Schiarra. Harper and Row, Philadelphia.

Vickery, B.H. \& McRae, G.I. (1980) Effects of continuous treatment of male baboons with superagonists of LHRH. Int. J. Fertil. 25, 179-184.

Wang, N.-G., Sundaram, K., Pavlou, S., Rivier, J., Vale, W. \& Bardin, C.W. (1983) Mice are insensitive to the antitesticular effects of LHRH agonists. Endocrinology 112, 331-335.

Wickings, E.J. \& Nieschlag, E. (1980) Seasonality in endocrine and exocrine testicular functions of the adult rhesus monkey (Macaca mulatta) maintained in a controlled laboratory environment. Int. J. Androl. 3, 87-104.

Wickings, E.J., Usadel, K.H., Dathe, G. \& Nieschlag, E. (1980) The role of follicle stimulating hormone in testicular function of the mature rhesus monkey. Acta endocr., Copenh. 95, 117-128.

Received 24 January 1984 